\title{
The Study of Entrepreneurship Education in Yancheng Vocational Colleges
}

\author{
Zhang Zhenzhen ${ }^{1, a^{*}}$ and Gu Juan ${ }^{2, b}$ \\ 1 Jiangsu Vocational College of Medicine, Yancheng,Jiangsu, China \\ a 110553556@qq.com, b378649027@qq.com \\ * The corresponding author
}

Keywords: Higher vocational colleges; College students; Entrepreneurship education

\begin{abstract}
In this study, the historical evolution of College Students' entrepreneurship education is combed, the status of entrepreneurship education of higher vocational colleges in Yancheng city is investigated and analyzed, and the effective ways to carry out entrepreneurship education in higher vocational colleges are further discussed
\end{abstract}

\section{Introduction}

The development of higher vocational education is very good, but the employment situation of college students is still grim. In the third and fourth plenary sessions of the eighteen Central Committee, the party stressed that it should "guide the workers to change the concept of employment, encourage multiple channels and multiple forms of employment, and promote employment to promote employment." The "2016 employment report on Chinese college students" published by the Mike Research Institute (the blue book of employment) shows that entrepreneurship and further study are the main factors to stabilize the employment of college students. Entrepreneurship education is a long-term and personal life-long benefit of the country. Higher vocational colleges strengthen entrepreneurship education and promote college students to embark on their own business. It can effectively alleviate the problem of employment and promote the development of local economy and society. In this study, the historical evolution of College Students' entrepreneurship education is combed, taking two public vocational colleges in Yancheng as the research object, to investigate the existing problems of entrepreneurship education in Yancheng higher vocational colleges, and to further discuss the effective ways to carry out entrepreneurship education in higher vocational colleges.

\section{The Background of College Students' Entrepreneurship Education in Yancheng City}

In July 2004, the Ministry of education, the Ministry of labor and social security (now the Ministry of human resources and social security) sent a joint document to 37 colleges and universities in China to carry out entrepreneurship education centered on the SYB project, and the entrepreneurship education of college students in our country was carried out in an all-round way. The innovation and entrepreneurship education of universities in Jiangsu started in 2007. At present, 40 Provincial College Students' entrepreneurship education demonstration schools have been built, 50 provincial demonstration bases of provincial university students have been accepted, and 22 thousand and 800 Provincial College Students' innovative and entrepreneurial training programs are implemented.

In 2013, Yancheng City launched the three year action plan of Yancheng youth entrepreneurship, focusing on nurturing and supporting youth entrepreneurship projects. In October of the same year, the municipal government issued the "opinions on Further Encouraging the whole nation to start businesses" to encourage technology talents and university students to start their own businesses. In 2014, the leading group of Yancheng City talent work issued the three year action plan for high level talent in Yancheng City (2013 - 2015). In 2015, the municipal government of the CPC Yancheng municipal municipal government initiated the three year action plan for the introduction of the 
"Yancheng City" 515 "talent", and energetically gathered and encouraged high-level talents to innovate and start a business.

\section{The Present Situation of Entrepreneurship Education in Yancheng City Higher Vocational Colleges}

Achievements in Entrepreneurship Education in Yancheng Higher Vocational Colleges. First, the reform of innovative talents training mode has been continuously promoted, and the entrepreneurship education mode with different characteristics has been constructed. Jiangsu pharmaceutical Career Academy has formulated the implementation plan for deepening innovation and entrepreneurship education reform, and gradually formed the four platform of "class actual match", and practice "five in one" innovation and entrepreneurship education model. The Career Technical College industry has integrated professional education with innovation and entrepreneurship education, according to the characteristics of different professional groups. Set up the curriculum of innovation and entrepreneurship, introduce the design of the enterprise plan and innovation product, process and process into the course design, graduation design and social practice, and carry out the all-round teaching reform, and form a "four level progressive" entrepreneurship education which integrates "entrepreneurial cognition, entrepreneurial experience, entrepreneurship simulation and entrepreneurial real war". System.

The two is the continuous improvement of the curriculum system of entrepreneurship education. The basic courses of innovation and entrepreneurship, public elective courses and entrepreneurial practice are offered to students. The concept of entrepreneurship is penetrated into teaching, and teaching methods, methods and methods are reformed, heuristic, case, and discussion teaching methods are advocated to stimulate the students' enthusiasm for innovation and entrepreneurship, and to cultivate the creative and entrepreneurial thinking of the students. Three, the construction of entrepreneurial practice platform is constantly strengthened. Jiangsu medicine Career Academy gives full play to its professional advantages, relying on professional construction, successfully carrying out a number of College Students' entrepreneurship projects, and cooperating with the new Chengnan New District to build the first practice base of innovation and entrepreneurship for College Students - Xiang Yuan Xiyuan health cottage, to carry out health services to the outside world, and to complete college students in the Career Technical College of Yancheng industry The construction project of science and Technology Venture Park provides college students with the training base of the school enterprise cooperation entity company, the cooperative enterprise workstation, the teacher's studio, the corporation in the base of the base, the college student entrepreneurship guidance service station and the college student undertaking project hatching.

The Lack of Entrepreneurship Education in Yancheng Higher Vocational Colleges.The strength of the teachers of entrepreneurship education is relatively weak. The professionalism of the teachers of entrepreneurship education is not strong, and there is no professional entrepreneurship education teacher. It is mainly taught by student managers, counselors and ideological and political teachers, and lack of strict training of entrepreneurship education system and experience of entrepreneurial practice.

The construction of entrepreneurial practice platform is not perfect. There are not many practical bases for entrepreneurship education in higher vocational colleges, and the development and operation of entrepreneurial foundation are not very good. Only a few students are doing entrepreneurial practice, and the enterprises that can really participate in the practice of students' entrepreneurship can not be systematized and normalized.

\section{The Implementation of Entrepreneurship Education in Yancheng City Higher Vocational Colleges.}

Change the Concept of Entrepreneurship Education. Entrepreneurship education is to transform students' concept of passive employment into active entrepreneurial ideas, and encourage students to 
take entrepreneurship as their career choice. Colleges and universities should change the traditional education concept, improve the students' comprehensive quality and professional skills, and strengthen the cultivation of entrepreneurial consciousness, and integrate the entrepreneurial education as an important content of the training of talents into the teaching, and penetrate the whole process of the ideological and entrepreneurial education through the whole process of college education.

Strengthen the Construction of the Teaching Staff of Entrepreneurship Education. The first is to select the excellent teachers with advanced innovation and entrepreneurship education ideas and methods to set up the teaching and Research Department of innovation and entrepreneurship, and focus on the knowledge teaching of the basic theory of innovation and entrepreneurship and the frontier of the subject. Two is to employ the famous entrepreneurs who are familiar with Entrepreneurship and entrepreneurial experience and the outstanding alumni with experience of entrepreneurship as part time innovation and Entrepreneurship Education Teachers or entrepreneurial mentors, undertake certain teaching tasks, set up lectures, carry out case discussion and business practice guidance, and so on. Three is to formulate training programs for innovative and entrepreneurial courses, professional title evaluation, scientific research funds and other preferential policies, and to improve the business ability of innovative and entrepreneurial teachers.

Perfect the Curriculum System of Entrepreneurship Education. The curriculum system of entrepreneurship education should include the comprehensive cultivation of College Students' entrepreneurial consciousness, entrepreneurial psychological quality and entrepreneurial knowledge and skills. "2016 Chinese college students' report on entrepreneurship" also shows that contemporary college students also attach great importance to the value of college professional knowledge for entrepreneurship. The report suggests that colleges and universities should provide different students with more emphasis and more accurate entrepreneurship education. The higher vocational colleges should take the entrepreneurship education to all the students and combine the practice of professional education to the whole process of talent training, especially the integration of entrepreneurial education and professional education, and integrate the entrepreneurial curriculum into the public basic courses, professional basic courses and professional skills courses, so as to integrate the entrepreneurial education into the course. To all aspects of the course teaching. In addition, we should strengthen the education link of entrepreneurial practice, and guide the students to integrate the knowledge and actual production by carrying out the activities of entrepreneurship research and enterprise visits.

Build a Diversified Entrepreneurial Practice Platform. We should actively guide and encourage students to take part in extracurricular entrepreneurial practice activities, accumulate entrepreneurial knowledge through practice, cultivate entrepreneurial ability and establish entrepreneurial confidence. Conscientiously implement the project of College Students' practice training program for innovation and entrepreneurship; organize teachers and students to participate in the activities of all kinds of innovation and entrepreneurship competitions at all levels, select and cultivate the advantages of the project. Through the competition, the college students who have the consciousness of innovation and entrepreneurship are involved in the docking enterprise, for the approval of the venture capital institutions, the policy of government support and the promotion of the fall of the venture. We should promote the construction of university students' Pioneering Park and practice base, and establish a comprehensive and ladder shaped business incubation service system for university students.

Create a Entrepreneurial Atmosphere, Provide Support for Entrepreneurship. Since the implementation of entrepreneurship education in Colleges and universities, the relevant state ministries and local governments have promulgated a series of policies to support the employment of college students, create a entrepreneurial atmosphere, and provide support for entrepreneurship. The school should also strengthen the construction of campus culture of entrepreneurship education, set up a number of college students to start a business, encourage college students to set up their own business, start a business to drive employment, strive to create a harmonious environment for entrepreneurship and a good atmosphere, and stimulate the potential of innovation and Entrepreneurship. At the present stage, the practice of College Students' Entrepreneurship also faces many challenges, among which the two major resistance factors that restrict the practice of college students are the lack of funds and 
experience of the college students' entrepreneurs. Schools should publicize various policies to promote college students' entrepreneurship through SMS, micro-blog, WeChat and mobile Internet platform, and guide students to make good use of their policies.

\section{References}

[1] Shen Jian. Construction of innovation and entrepreneurship education ability of University Teachers: understanding, practice and conception of Jiangsu [J]. higher education in China, 2015, (17): 11-13.

[2] Jiang Liwen, Li Jingguo, Ding Wei. Review and Reflection on College Students' entrepreneurship education since reform and opening up [J]. Heilongjiang higher education research, 2016, (04): 90-93.

[3] Xiao Yan Hui. An overview of the history of entrepreneurship education in Chinese universities. [J]. science and technology entrepreneurship monthly, 2011, (06): 17-18.

[4] Jiangsu province people's Association office. Take four actions to cultivate the entrepreneurial Paradise -- a review of the implementation of Jiangsu university students' entrepreneurship guidance plan [J]. China's employment, 2016, (05): 8-11.

[5] Renmin University of China. "2016 China entrepreneurship report" [R].2016.

[6] Mike Research Institute. 2016 Chinese college student employment report [R].2016 
